\title{
Extensive Sprouting of Sensory Afferents and Hyperalgesia Induced by Conditional Expression of Nerve Growth Factor in the Adult Spinal Cord
}

\author{
Mario I. Romero,, ${ }^{1}$ Nagarathnamma Rangappa, ${ }^{2}$ Li Li, ${ }^{1}$ Ellis Lightfoot, ${ }^{1}$ Mary G. Garry, ${ }^{1}$ and George M. Smith ${ }^{2}$ \\ ${ }_{1}^{1}$ Department of Anesthesiology and Pain Management, University of Texas Southwestern Medical Center, Dallas, Texas \\ 75235, and 2Department of Physiology, University of Kentucky, Albert B. Chandler Medical Center, Lexington, Kentucky \\ 40536-0298
}

Genetic transfer of growth-promoting molecules was proposed as a potential strategy to modify the nonpermissive nature of the adult CNS to induce axonal regeneration. To evaluate whether overexpression of neurotrophins or cellular adhesion molecules would effect axonal plasticity, adenoviruses encoding fibroblast growth factor-2 (FGF-2/Adts), nerve growth factor (NGF/Adts), neurotrophin-3, and the cell adhesion molecules $\mathrm{N}$-cadherin and L1 were injected into the dorsal horn of the adult spinal cord. Transgene expression was primarily localized to astrocytes in the dorsal horn and motor neurons within the ventral horn. Overexpression of these factors, with the exception of NGF/Adts, failed to increase axonal sprouting. Eight days after NGF/Adts injections, axonal sprouting within the dorsal horn was apparent, and after 4 weeks, extensive spouting was observed throughout the entire dorsal horn, extending into the ventral horn and the white matter of the lateral funicu- lus. These axons were identified primarily as a subpopulation of nociceptive fibers expressing calcitonin gene-related peptide and substance-P. Behavioral analysis revealed thermal hyperalgesia and perturbation of accurate paw placement on gridwalking tasks for both FGF-2- and NGF-treated animals. These results indicate that the administration of growth-promoting molecules can induce robust axonal plasticity of normal adult primary sensory neurons into areas of transgene expression, causing significant alterations in behavioral responses. This observation also indicates that gene transfer protocols that aim to reconstruct diseased or injured pathways should also be designed to prevent the sprouting of the normal circuitry from adjacent unaffected neurons.

Key words: gene therapy; regeneration; neurotrophins; chronic pain; spinal cord; adenovirus
Failure of neurons to spontaneously regenerate after injury in the adult CNS is thought to be the result of the nonpermissive nature of the CNS environment (Aubert et al., 1995), which is due to the lack of growth-promoting molecules (Varon and Conner, 1994) and the presence of inhibitory molecules (Schwab and Bartholdi, 1996; Fitch and Silver, 1999). Providing a growth supportive environment by the administration of neurotrophic factors (NTFs) (Lindsay et al., 1994) or the blockade of growth inhibitory molecules (Guest et al., 1997) is partially successful at inducing axonal regeneration within the adult CNS. In addition, cellular adhesion molecules (CAMs) also play an important role in supporting axonal growth and regeneration, because they are involved in mediating neurite outgrowth, axon fasciculation, pathfinding, and changes in growth cone morphology (Hortsch, 1996; Walsh and Doherty, 1997; Honig et al., 1998).

Early attempts to supply neurotrophins by systemic administration revealed deleterious side effects and illustrated the need for safer and more efficient delivery systems (Dijkhuizen and Ver-

Received Aug. 25, 1999; revised March 27, 2000; accepted March 29, 2000.

This study was supported by the J. F. Maddox Foundation and National Institutes of Health Grants NS33776 and NS38126 (G.M.S.) and GM 58057 (M.G.G.), and the Daniel Heumann Spinal Cord Foundation (M.I.R.). The expert technical assistance of Michael Davis, Jason Hale, and Martha Romero is greatly appreciated.

Correspondence should be addressed to Dr. George M. Smith, Department of Physiology MS 508, University of Kentucky, Albert B. Chandler Medical Center, Lexington, KY 40536-0298. E-mail: george.smith@pop.uky.edu.

Dr. Romero's present address: Center for Developmental Biology, University of Texas Southwestern Medical Center, Dallas, TX 75235.

Copyright $\odot 2000$ Society for Neuroscience $0270-6474 / 00 / 204435-11 \$ 15.00 / 0$ haagen, 1999; Tuszynski, 1999). Subsequent studies focused on the manipulation of the CNS environment primarily through gene transfer protocols (Holtmaat et al., 1998; Senut et al., 1998). In the spinal cord, the use of primary fibroblasts engineered to secrete NTFs induced growth of both sensory and motor fibers (Tuszynski et al., 1994; Nakahara et al., 1996). Similarly, L1expressing fibroblasts grafted into a lesion cavity provided a growth substrate that enhanced axonal regeneration (Kobayashi et al., 1995). However, tumor formation and immune-mediated graft rejection are main concerns for the application of ex vivo gene therapy-based strategies (Senut et al., 1998). In vivo gene transfer methods represent a viable alternative for the continuous and long-term delivery of growth supportive molecules (Hermens and Verhaagen, 1998; Smith and Romero, 1999). The use of recombinant replication-defective adenovirus to mediate the gene transfer of NT-3 or CNTF resulted in increased neuronal survival and enhanced axonal growth (Smith et al., 1996; Djikhuizen et al., 1997; Zhang et al., 1998). In addition, adenovirusmediated gene transfer of neurotrophins increased motor neuron survival after facial nerve injury (Gravel et al., 1997; Baumgartner and Shine, 1998), rescued dopaminergic neurons in a mouse model of Parkinson's disease (Choi-Lundberg et al., 1997), and induced sprouting of motor terminals in the pmn (progressive motor neuropathy) mutant mouse (Haase et al., 1997).

Despite the well known trophic and tropic properties of NTFs and CAMs, very little is known about the feasibility for long-term expression of these molecules in the adult spinal cord. The possibility of deleterious side effects induced by the ectopic ex- 
pression of growth-promoting molecules, such as aberrant collateral sprouting and/or altered sensorimotor behavior has not been investigated. This study shows that adenoviral-mediated gene transfer induces discrete in vivo expression of growth-promoting and growth-permissive molecules within the injected region of the dorsal horn of the adult rat spinal cord. Although most of the factors showed no effect, the expression of NGF resulted in massive axonal growth of sensory neurons throughout the dorsal horn and into the ventral horn, affecting nociceptive- and proprioceptive-mediated behaviors.

\section{MATERIALS AND METHODS}

Animals. Fifty-four adult (250-350 gm) Sprague Dawley rats (Harlan Sprague Dawley, Indianapolis, IN) were used in this study (FGF-2/Adts, 12 rats; NGF/Adts, 14 rats; NT-3/Adts, 12 rats; N-cadherin (N-Cad)/ Adts, 5 rats; L1/Adts, 5 rats, and LacZ/Adts, 6 rats). The animals were maintained under conditions of controlled light and temperature. Food and water were available ad libitum. Institutional Animal Care and Research Advisory Committee regulations were observed for surgical, behavioral, and care procedures.

Construction of adenoviral vectors. Replication-defective recombinant adenoviruses were constructed as described previously (Romero and Smith, 1998). The coding regions of FGF-2 (gift from Dr. A. Baird, Ciblex Corporation), N-cad (gift from Dr. M. Takeichi, Kyoto University), L1 (gift from Dr. W. B. Stallcup, Burnham Institute), NGF (Regeneron), and NT-3 (gift from Dr. T. Large, Case Western Reserve University) were inserted into a modified pXCJL vector (gift from Dr. Frank Graham, McMaster University) containing the Rous sarcoma virus long terminal repeat and the bovine growth hormone polyadenylation. A flag peptide epitope was inserted at the $\mathrm{C}$ terminus of the FGF-2, N-Cad, NGF, and NT-3 cassettes to facilitate discrimination from endogenous molecules. Recombinant temperature-sensitive adenoviruses (Adts) were generated, plaque-purified, and isolated on a cesium chloride gradient as described by Romero and Smith (1998). The viral particle to plaque-forming unit (pfu) ratios for these viruses ranged between 123:1 and 260:1.

Western blot and functional analyses of CAMs and NTFs. The expression of CAMs and neurotrophins was evaluated $72 \mathrm{hr}$ after transfection of cultured astrocytes at several viral concentrations. Astrocyte monolayers treated with NCAM/Adts, N-Cad/Adts, or L1/Adts were solublized by the addition of $200 \mu \mathrm{l}$ of Laemmli's buffer to each of the wells of a 24-well plate. For astrocytes treated with either NGF/Adts or FGF-2/ Adts, identical amounts $(500 \mu \mathrm{l})$ of supernatant were precipitated in 10 vol of acetone at $-20^{\circ} \mathrm{C}$ overnight. Proteins were pelleted by centrifugation at 15,000 rpm, dried, and resuspended in $100 \mu \mathrm{l}$ Laemmli's buffer. To each well of either $7.5 \%$ (for CAMs) or $14 \%$ (for NTFs) SDSpolyacrylamide gel was added $40 \mu \mathrm{l}$ of sample. After running the gel, proteins were transferred to polyvinylidene difluoride membranes. Membranes were blocked using 5\% nonfat dry milk in Tris-buffered saline with $0.05 \%$ Tween-20 (TBST). Proteins of interest were identified using mouse anti-human L1 (monoclonal 74-5H7; gift from Dr. V. Lemmon, Case Western Reserve University) or mouse anti-FLAG (M2 antibody; Sigma, St. Louis, MO) in blocking solution. After a $3 \mathrm{hr}$ incubation in primary antibody, the membranes were washed five times, $10 \mathrm{~min}$ in TBST, and incubated in goat anti-mouse IgG (1:7500; Promega, Madison, WI) conjugated with alkaline phosphatase for $2 \mathrm{hr}$. Membranes were washed as above and developed using 5-bromo-4-chloro-3-indolyl phosphate/nitro blue tetrazolium solutions (Boehringer Mannheim, Indianapolis, IN).

Adhesion assays were performed following the procedure of Brackenbury et al. (1977). For these experiments, human embryonic kidney (HEK) 293 cells were treated with NCAM/Adts, N-Cad/Adts, L1/Adts, and green fluorescent protein (GFP)-encoding Adts (GFP/Adts; 1 pfu/ cell) for $24 \mathrm{hr}$ at $39^{\circ} \mathrm{C}$ (a nonpermissive temperature for replication of temperature-sensitive adenovirus). Cell monolayers were treated with mild trypsin $(0.25 \%$ for $10 \mathrm{~min})$, dissociated into a suspension of single cells, and pelleted by centrifugation. Cells were resuspended in DMEM culture media containing $10 \mathrm{mg} / \mathrm{ml} \mathrm{BSA}$ and $0.05 \mathrm{mg} / \mathrm{ml} \mathrm{DNase,} \mathrm{counted,}$ and diluted to $10^{7}$ cells $/ \mathrm{ml}$. Glass scintillation vials containing cell suspensions were placed in a shaking incubator (Labline) with a rotational speed of $75 \mathrm{rpm}$ and incubated for $0,15,30$, and $45 \mathrm{~min}$ at $37^{\circ} \mathrm{C}$. At the indicated times, the number of cells was determined using a Coulter Counter. Cell adhesion was verified using a light microscope and evident as an increase in the number of cell aggregates and a reduction in the number of single cells.

Functional expression of NGF was determined by examining the increased in neuronal survival from dorsal root ganglia (DRG). For these experiments, astrocytes were transduced using LacZ/Adts $(10 \mathrm{pfu} / \mu \mathrm{l})$ or NGF/Adts ( 25 pfu/cell) overnight. The next day the medium was removed, and fresh $\mathrm{N} 2$ serum-free medium was added. After $2 \mathrm{~d}$ the conditioned medium was removed, diluted in serum-free medium, and added to DRG cultures. Quantitative analysis of DRG neuronal survival was performed using the MTT method described previously by Manthorpe et al. (1986). To confirm the functional expression of FGF-2, cell proliferation was evaluated after transfection of serum-deprived 3T3 fibroblasts with FGF-2/Adts or LacZ/Adts. Twelve hours after transfection, the medium was replaced with fresh serum-free medium containing $10 \mu \mathrm{M}$ bromodeoxyuridine (BrdU) and incubated at $37^{\circ} \mathrm{C}$ for $16 \mathrm{hr}$. Uptake of BrdU was then determined by ELISA as described by Wemme et al. (1992).

Spinal surgery and adenovirus administration. Deeply anesthetized animals (intraperitoneal injection of a mixture of $67 \mathrm{mg} / \mathrm{kg}$ ketamine $/ 6.7$ $\mathrm{mg} / \mathrm{kg}$ xylazine) underwent hemilaminectomies at the T13-L1 vertebral segments. Animals received $100 \mu \mathrm{g}$ (i.p.) of a 50:50 mixture of rat CD-4 (W3/25) and CD-45 (MRC OX-22) antisera for transient suppression of the immune system for extended transgene expression (Romero and Smith, 1998). After exposure of the spinal cord, each animal received eight injections $(0.4 \mu \mathrm{l} ; 0.4 \mathrm{~mm}$ apart and $0.5 \mathrm{~mm}$ deep) of individual adenoviral vectors $\left(7.5 \times 10^{6} \mathrm{pfu} / \mu \mathrm{l}\right)$ along the L4-L5 dorsal root entry zone using a beveled glass micropipette and a Nanoject injector (Drummond Scientific, Broomall, PA). Dorsal musculature was then sutured, the skin incision was closed using wound clips, and prophylactic antibiotic treatment was applied to the wound. The animals were placed on a $37^{\circ} \mathrm{C}$ heat pad and monitored continually until recovery from the effects of the anesthetic. At the end of the study the animals were perfused transcardially with $4 \%$ paraformaldehyde in buffered saline. After perfusion, the lumbar spinal cord was removed and post-fixed before it was transferred to a $30 \%$ sucrose solution for cryoprotection. Tissue sections 10 and 30 $\mu \mathrm{m}$ thick were cut on a cryostat and divided into five alternate sets. The tissue sections were used either immediately for histological analysis or stored in cryoprotectant solution at $-20^{\circ} \mathrm{C}$ until processed. To enhance the immunocytochemical visualization of secretable transgenes, some of the animals were treated with $1 \%$ colchicine through a soaked-gelfoam pad placed over the injected area in the spinal cord, 36-48 hr before perfusion.

ELISAs for NGF, FGF-2, and NT. Rats were injected with NGF, FGF-2, NT-3, or LacZ-expressing adenovirus as described above. Eight days after injection, rats were anesthetized, and a $6 \mathrm{~mm}$ segment of the ipsilateral spinal cord containing the L4 and L5 injected region was removed and immediately frozen. Noninjected spinal cords were used as controls. The tissues were further processed according to the manufacturers instructions (Promega or R\&D Systems), with the additional step of pretreating each sample using protein-G agarose to absorb the rodent IgGs. Homogenates were incubated with protein-G agarose (Boehringer Mannheim) overnight at $4^{\circ} \mathrm{C}$ while shaking. The samples were then assayed for protein using BCA kit (Pierce, Rockford, IL) and used for immunoassay; $100 \mu \mathrm{g} / \mathrm{ml}$ (100 ml/well) and $250 \mu \mathrm{g} / \mathrm{ml}(100 \mathrm{ml} /$ well $)$ of each sample was used for the assay. After development 96 -well plates were read at $450 \mathrm{~nm}$ using a BioTech E12a microplate reader.

Immunocytochemistry. Tissue sections were rinsed in PBS, $\mathrm{pH} 7.5$, incubated with $5 \%$ normal goat serum, and followed by a $24 \mathrm{hr}$ incubation period with polyclonal antiserum against rat calcitonin gene-related peptide (CGRP) (1:20,000; Sigma), substance-P (1:20,000; RBI, Natick, MA), or monoclonal antisera for the L1 (1:2) or FLAG epitope (1:1000). Visualization was achieved by tissue incubation in fluorescent or biotinylated secondary antibodies. Biotin-labeled tissue was further processed using the Vectastain "Elite" ABC reagents (Vector Laboratories, Burlingame, CA) and developed using a solution of hydrogen peroxide $(0.003 \%)$ and diaminobenzidine $(0.02 \%)$.

Double immunofluorescence was used to determine the specific phenotype of adenovirally transduced cells. After rinsing, tissue sections were simultaneously incubated with the $\mathrm{L} 1$ antiserum and a monoclonal antibody for either the glial fibrillary acidic protein (GFAP) (1:500; Chemicon, Temecula, CA.) or the nonphosphorylated form of neurofilament H (MSI-32) (1:500; Sternberger Monoclonals, Lutherville, MD). Visualization was achieved by simultaneous incubation in Texas Redlabeled goat anti-rabbit and fluorescein-labeled goat anti-mouse (1:250; Jackson Immunoresearch, West Grove, PA). Tissue sections of both 


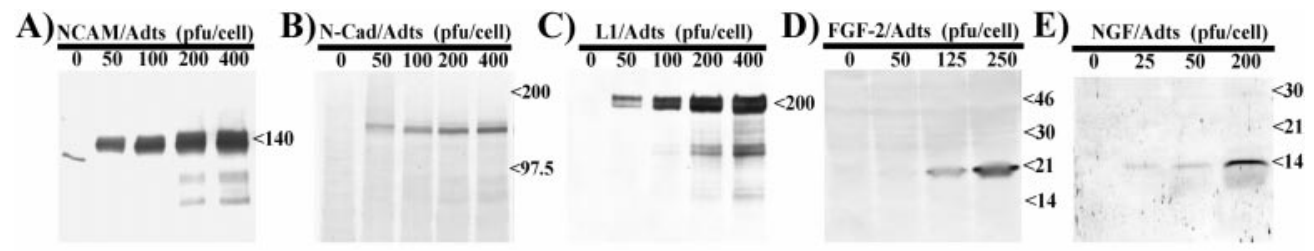

F) Adhesion Assay

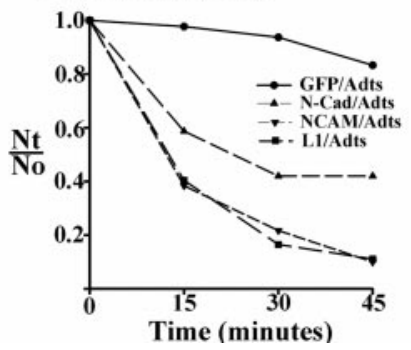

G) Proliferation of $3 \mathrm{~T} 3$ cells

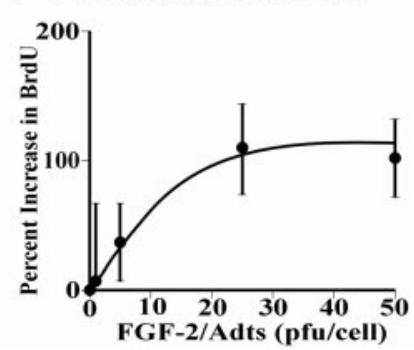

H) DRG Neuronal Survival

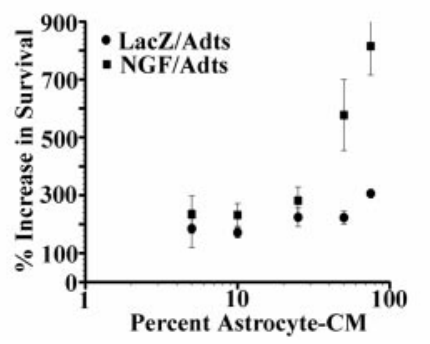

Figure 1. Western blot and functional analyses for adenovirus-encoding neural cell adhesion molecules $(A), \mathrm{N}$-cad $(B)$, and L1 $(C)$, fibroblast growth factor-2 $(D)$, or nerve growth factor $(E)$. Western blots of primary astrocytes demonstrate dose-dependent increases in transgene expression with increased virus titer. Western blots of FGF-2/Adts $(D)$ and NGF/Adts $(E)$ are of proteins that were secreted into conditioned medium, whereas the other Western blots $(A-C)$ are of proteins isolated from monolayers. $F$, Adhesion assays on cell suspensions pretreated with NCAM/ Adts, N-Cad/Adts, and L1/Adts show a reduction in the number of single cells and thus an increase in cell aggregates with increased time. Abscissa represents the ratio of single cells measured at the time indicated on the ordinate $(N t)$ divided by the number before incubation $(\mathrm{No})$. Very little change in cell aggregation was observed by cells pretreated with control virus $(G F P / A d t s)$. $G$, The addition of FGF-2/Adts to $\sim 25$ pfu per cell caused a dose-dependent increase in the incorporation of BrdU into 3 T3 fibroblasts as determined by ELISA. $H$, Conditioned medium from primary astrocytes pretreated with NGF/Adts increased the survival of DRG neurons approximately fivefold when compared with that conditioned medium from astrocytes pretreated with LacZ/Adts. The number of surviving DRG neurons depended on the concentration of the conditioned medium from NGF/Adts-treated astrocytes.

control and experimental groups were simultaneously developed using identical incubating solutions. Sections were mounted on gelatinized slides and coverslipped with Permount or $5 \% n$-propyl-gallate in glycerol for light and fluorescence microscopy examination, respectively. Exclusion of any of the primary antisera from the staining protocol rendered no specific staining.

Fluoride-resistant acidic phosphatase histochemistry. Tissue sections were rinsed in PBS and then incubated in a solution containing $2 \mathrm{~mm}$ $\mathrm{MgCl}_{2}, 5 \mathrm{~mm} \mathrm{~K}_{3} \mathrm{Fe}(\mathrm{CN}) 6,5 \mathrm{~mm} \mathrm{~K}_{4} \mathrm{Fe}(\mathrm{CN}) 6,0.01 \%$ deoxycholate, and $0.02 \%$ Tween 20 , adjusted at $\mathrm{pH} 5$. Visualization of the fluoride-resistant acidic phosphatase (FRAP) enzyme was achieved by adding 5-Br-4-Cl3 -indol phosphate $(1.5 \mathrm{mg} / \mathrm{ml})$ as a substrate and allowed to react for $1 \mathrm{hr}$ at room temperature. After extensive rinsing in distilled water, the sections were mounted on gelatinized slides and coverslipped with Permount.

Image analysis method. Animals treated with respective adenoviral vectors were assessed for an increase in total CGRP-immunoreactive area at either $8 \mathrm{~d}(n=5$ rats per treatment) or $32 \mathrm{~d}(n=3$ rats per treatment) after injection into the spinal cord. Four CGRP-stained sections (two at L4 and two at L5) of the dorsal horn at the site of the injection were digitized per animal (200× magnification). The images were then analyzed using the NIH Image 1.62 software. Threshold and resized images $(57 \%)$ were used to determine the total pixel area within two square zones $(108 \times 216$ pixels $)$. These were located either in the midline of the dorsal horn spanning laminas I-III (zone $A^{\prime}$ as shown in Fig. $3 B$ ), or below lamina III in the lateral dorsal horn (zone $B^{\prime}$ as shown in Fig. $3 B$ ). The values were then compared using a one-way ANOVA and a Student's-Newman-Keuls post hoc test. Values below 0.05 were considered significant.

Thermal nociception. The latency of paw withdrawal to radiant heat was used as a measure of response to a noxious thermal stimulation as described previously (Hargreaves et al., 1988; Garry et al., 1994). Rats were placed beneath an inverted clear plastic chamber on a glass floor. After a 5 min habituation period, the plantar surface of the paw was exposed to a beam of radiant heat applied through the glass floor. Paw withdrawal latency (PWL) was automatically detected by a photocell and was taken as a behavioral index of the nociceptive threshold. Therefore, a score that was significantly lower than baseline indicated hyperalgesia. Conversely, a score that was significantly higher than baseline represented analgesia (antinociception). A cutoff time of $20 \mathrm{sec}$ was implemented to ensure that no tissue damage occurred to the paw. Individuals conducting these experiments were always blinded as to the treatment. PWL readings were always taken in duplicate at $\sim 10$ min intervals. All animals were examined before adenoviral injections to establish baseline latencies, after which testing was performed on a weekly basis.

Statistical analysis. The effects of treatment and time on the percentage of accurate paw placement and latency of paw withdrawal were evaluated by two-factor ANOVA with repeated measures (Super ANOVA program, Abacus Concepts, Berkeley, CA, and BMDP, statistical software, Los Angeles, CA.). Student's and Duncan post hoc analyses were used to determine significant differences within treatments. Data represent the mean \pm SEM. $p$ values below the $5 \%$ probability level were considered significant.

\section{RESULTS}

\section{Functional characterization of adenoviral-mediated expression of CAMs and NTFs}

Adenoviral-mediated expression of cellular adhesion molecules and neurotrophins was first evaluated by treating primary astrocytes with increasing concentrations of the respective viral constructs. Protein expression was examined by both Western blot and functional analyses, because many of the cDNA constructs were modified to produce a fusion protein containing an eight amino acid FLAG sequence at the $\mathrm{C}$ terminus. In addition, FGF-2 was further modified at the $\mathrm{N}$ terminus to encode the IgG-signal sequence for secretion. Western blot analysis revealed a concentration-dependent increase in the expression of the respective transgenes $48 \mathrm{hr}$ after viral administration (0-400 pfu/ cell) (Fig. $1 A-E)$. Immunodetection of the transgenes revealed that the expression of L1 ( $200 \mathrm{kDa}), \mathrm{N}-\mathrm{Cad}(\sim 135 \mathrm{k} \mathrm{Da})$, and NCAM $(\sim 140 \mathrm{kDa})$ was confined to the astrocyte monolayer, whereas NGF $(\sim 14 \mathrm{kDa})$ and FGF-2 $(\sim 18 \mathrm{kDa})$ were identified as secreted products within the tissue culture supernatants.

To verify biological function of the transgene product, adhesion assays, proliferation assays, and neuronal survival assays were performed on the adenoviral-transfected cells. To examine the functional expression of CAMs, HEK293 cells were transfected with L1, N-Cad, NCAM, or GFP (negative control) adenoviruses. Twenty-four hours later, measurements of cell suspensions showed an increase in the number of aggregates of cells treated with L1/Adts, N-Cad/Adts, or NCAM/Adts, but not GFP/ Adts (Fig. $1 F$ ). To examine the function of FGF-2, 3 T3 cells were infected with FGF-2/Adts and treated with BrdU 12 hr later. ELISA analysis showed a more than twofold increase in BrdU incorporation when normalized to $3 \mathrm{~T} 3$ cells treated with LacZ/ 
Figure 2. Photomicrographs of coronal $(A, B)$ and sagittal $(C)$ sections of the L4-L5 lumbar spinal cord showing the extent and localization of NT-3 $(A), \mathrm{L} 1$ $(B)$, and $\mathrm{N}-\mathrm{Cad}(C), 8 \mathrm{~d}$ after transfection. Gene transfer was observed on cells located throughout the dorsal horn $(D H)$ and in the ventral motor neurons $(V M N)$ ipsilateral to the injection. Spinal cords injected with L1/Adts were double-labeled with antibodies specific to human L1 $(D, F)$ and either GFAP $(E)$ or neurofilament $(G) . D, E$, Most of the L1-positive cells in both the gray and white matter of the dorsal spinal cord were GFAP-positive astrocytes (arrowheads). Transgene expression was apparent extending to the dorsal root entry zone (arrows). F, $G$, Within the ventral horn, most of the L1-positive cells coexpressed neurofilament (small arrows) and had a morphology reminiscent of motor neurons. Scale bars indicate magnification.

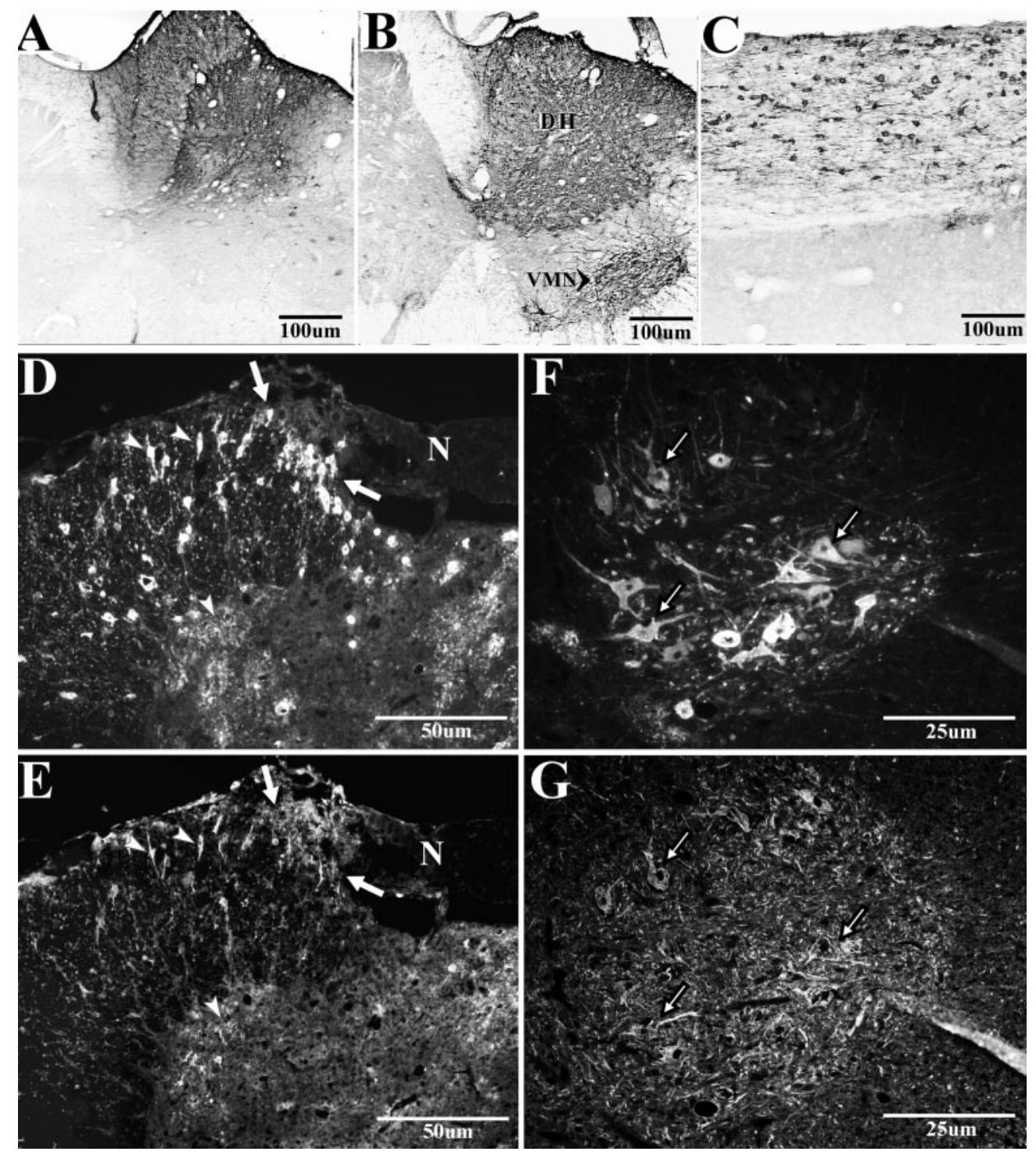

Adts (Fig. 1G). We have previously characterized the biological function of several adenoviral-expressed neurotrophic factors, including NT-3 (Smith et al., 1996). Using a similar procedure we determined that conditioned medium from astrocytes transduced with NGF/Adts increased DRG neuronal survival greater than fivefold when compared with conditioned medium from astrocytes transduced with LacZ/Adts (Fig. $1 H$ ). Together these data show that protein modification, such as the $\mathrm{IgG}$ signal sequence and FLAG epitope, did not inhibit protein expression or function.

\section{Expression of CAMs and NTFs in the adult spinal cord}

Our previous studies using LacZ/Adts showed that the microinjection procedure consistently results in transgene expression throughout the dorsal horn (Romero and Smith, 1998). This procedure was repeated with all of the adenoviruses to further examine the distribution and relative expression levels of both CAM and NTF transgenes within the spinal cord. Eight days after adenovirus administration, robust transgene expression was observed, although a relatively low amount $\left(3 \times 10^{6} \mathrm{pfu} / \mu \mathrm{l}\right)$ of virus was injected at each injection site. Consistent with previous results, this expression was concentrated within the dorsal horn on the injected side of the spinal cord (Fig. 2). In coronal sections,
NT-3 (Fig. 2A) and L1 (Fig. 2B) staining is apparent throughout the dorsal horn, with some transgene expression appearing within motor neurons (Fig. 2B). A similar staining pattern was observed after injection of LacZ/Adts, NGF/Adts, FGF-2/Adts, and N$\mathrm{Cad} /$ Adts. The level of transgene expression was relatively constant throughout the injected area and, as described previously, peaked between 7 and $14 \mathrm{~d}$ after adenoviral injection (Romero and Smith, 1998). Longitudinal sections of animals injected with $\mathrm{N}$-Cad/Adts (Fig. 2C) show N-cadherin-positive cells within the dorsal columns with a morphology reminiscent of astrocytes. In these animals, the transduced cells showed apparent normal neuronal and glial morphology, and there was little evidence of cell death or tissue damage induced by the treatment. However, in some sections, minor tissue damage was observed in white matter tracts, most likely because of the higher vulnerability of oligodendrocytes to the cytotoxic effects of adenovirus (Byrnes et al., 1995).

To quantify the in vivo expression levels for the neurotrophins, several commercially available ELISA kits for NT-3, NGF, and FGF-2 were examined. Of these kits, only the NGF kit showed low background activity and cross-reactivity to rat NGF. In the spinal cord of noninjected animals, NGF was measured at a 

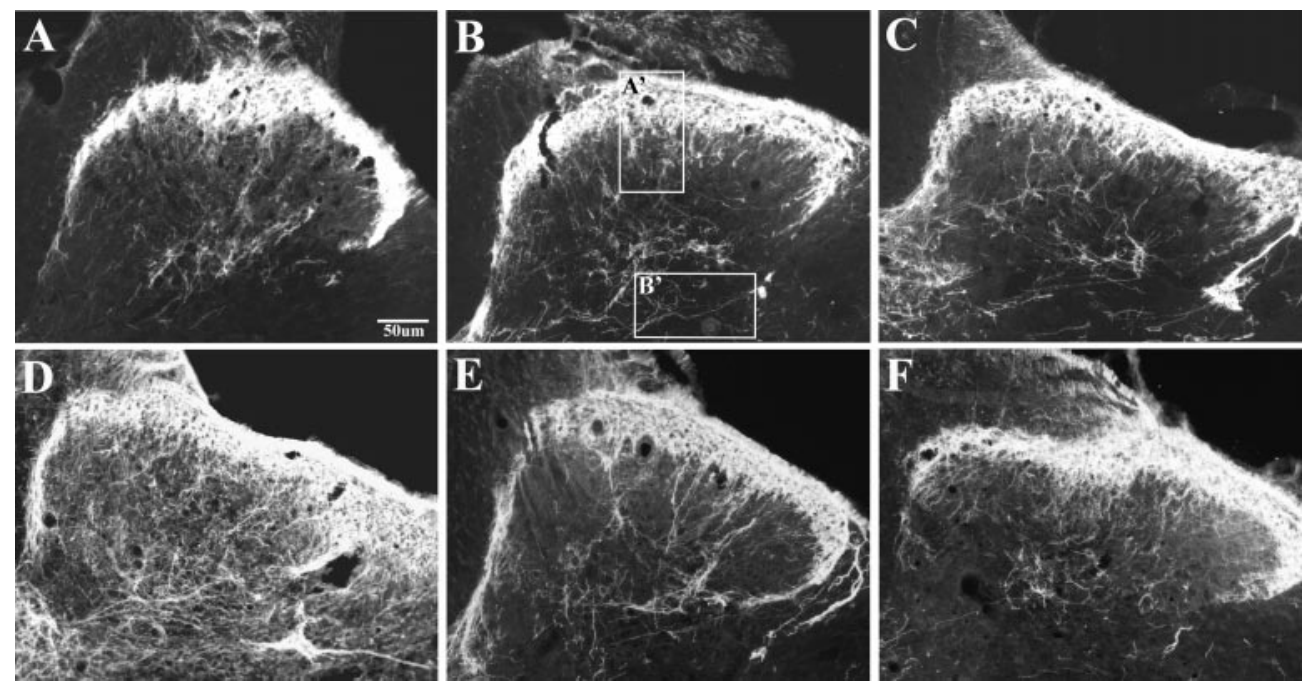

Figure 3. Immunocytochemical visualization of CGRP-containing primary afferents in the dorsal horn of the lumbar spinal cord in animals treated with either LacZ $(A)$, FGF-2 $(B)$, L1 $(C)$, NGF $(D), \mathrm{N}-\mathrm{Cad}(E)$, or NT-3 $(F)$ at $8 \mathrm{~d}$ after transfection. With the exception of NGF-treated animals, the induced expression of growth-promoting molecules in the dorsal spinal cord did not alter the normal innervation pattern of CGRP nociceptors. In contrast, NGF induced extensive sprouting of CGRP-positive axons throughout the transduced area $(D)$. The digitalized images were contrast-inverted to provide better recognition of stained axons. The insets $\left(A^{\prime}\right.$, $\left.B^{\prime}\right)$ in $B$ illustrate the location and relative size of the areas used to obtained the data described in Table 1. Scale bar: $B-F$ same as $A$.

Table 1. Quantitative measurement of axon sprouting into the dorsal horn after adenoviral treatment

\begin{tabular}{|c|c|c|c|c|}
\hline \multirow[b]{2}{*}{ Treatment } & \multicolumn{2}{|c|}{$8 \mathrm{~d}$ after injection ${ }^{a}$} & \multicolumn{2}{|c|}{$32 \mathrm{~d}$ after injection ${ }^{a}$} \\
\hline & Lamina I-III & Lamina V and VI & Lamina I-III & Lamina V and VI \\
\hline None & $1.79 \pm 0.44$ & $0.021 \pm 0.029$ & & \\
\hline LacZ/Adts & $1.82 \pm 0.40$ & $0.042 \pm 0.032$ & & \\
\hline N-Cad/Adts & $1.91 \pm 0.24$ & $0.005 \pm 0.007$ & & \\
\hline L1/Adts & $1.83 \pm 0.25$ & $0.009 \pm 0.016$ & & \\
\hline NT-3/Adts & $1.96 \pm 0.41$ & $0.010 \pm 0.019$ & $1.80 \pm 0.20$ & $0.007 \pm 0.008$ \\
\hline NGF/Adts & $2.27 \pm 0.45^{*}$ & $0.215 \pm 0.161^{* *}$ & $2.39 \pm 0.35^{* *}$ & $2.672 \pm 0.441^{* *}$ \\
\hline FGF-2/Adts & $1.96 \pm 0.25$ & $0.008 \pm 0.017$ & $1.93 \pm 0.22$ & $0.004 \pm 0.005$ \\
\hline
\end{tabular}

Each treatment represents data taken from not less than three rats. $\pm \mathrm{SD} ;{ }^{*} p>0.05,{ }^{*} p>0.01$.

${ }^{a}$ Optical density measurement indicating axon densities taken from individual regions in lamina I-III (illustrated as $A^{\prime}$ in Fig. $3 B$ ) or lamina $\mathrm{V}$ and VI (illustrated as $B^{\prime}$ in Fig. $3 B$ ).

concentration of $0.517 \pm 11 \mathrm{ng} / \mathrm{mg}$ of protein. This level did not statistically differ after the injection of the control adenovirus (LacZ, $0.608 \pm 69 \mathrm{ng} / \mathrm{mg}$ ); however, injection of either FGF-2/ Adts or NGF/Adts resulted in an increase in the concentration of NGF by $190 \%(0.981 \pm 212 \mathrm{ng} / \mathrm{mg}$ protein; $p>0.05)$ and $938 \%$ $(4.85 \pm 626 \mathrm{ng} / \mathrm{mg}$ of protein; $p>0.001)$, respectively.

To examine the cell types that expressed the transgene, sections from animals injected with L1/Adts were double-labeled with anti-human L1 (Fig. 2D,F) and either GFAP (Fig. 2E) or anti-neurofilament (Fig. $2 G$ ). Throughout the dorsal spinal cord, transgene expression was primarily localized to astrocytes within the white and gray matter. This transgene expression extended all the way to the dorsal root entry zone (Fig. 2D,E). In some animals, Schwann cells within the dorsal roots also expressed the transgene. Within the ventral horn, the motor neurons were the primary cell type expressing the transgene (Fig. $2 F, G$ ). Because adenoviruses injected into the dorsal horn do not appear to diff use into the ventral horn, the virus may become accessible to motor neurons by endocytosis into dendrites that extend dorsally. Of all the neurons within the spinal cord, motor neurons have been shown to efficiently uptake and express recombinant adenoviruses (Gravel et al., 1997; Baumgartner and Shine, 1998).

\section{Extensive outgrowth of sensory primary afferents induced by NGF/Adts}

The central afferents from small-caliber cutaneous sensory fibers (A-delta and C fibers) terminate primarily in lamina I and II of the dorsal horn, with some projections to lamina V and X. These afferents can be specifically visualized by their content of CGRP, which serves as a specific marker for these fibers within the spinal cord (Gibson et al., 1984; Chung et al., 1988). To test whether the overexpression of CAMs and NTFs in the spinal cord alter the normal innervation pattern of these axons, animals that received injections of CAMs and NTFs containing adenoviruses were evaluated $8 \mathrm{~d}$ later for CGRP immunoreactivity. The dorsal horn from either sham-operated controls, LacZ/Adts-injected controls, or the contralateral side of all adenoviral-injected spinal cords displayed a CGRP-containing fiber pattern similar to that of normal nonoperated animals (Fig. $3 A$ ). The induced expression of L1 (Fig. 3C), N-Cad (Fig. 3E), FGF-2 (Fig. 3B), or NT-3 (Fig. $3 F)$ did not appear to affect the distribution of CGRPimmunoreactive axons. The spinal cords of animals treated with an NGF-encoding adenovirus, however, showed extensive innervation of CGRP-positive fibers throughout the dorsal spinal cord on the injected side (Fig. 3D). Assessments of optical densities for CGRP-positive fibers within two separate regions extending throughout either lamina I and II or the lateral portion of lamina $\mathrm{V}$ and VI demonstrate that CGRP-positive fiber density greatly increased within both of these regions after treatment with $\mathrm{NGF} /$ Adts, but not the other recombinant adenoviruses (Table 1). The growth of the CGRP-immunoreactive fibers into the transduced area (Fig. 3, compare $A, D$ ) clearly demonstrates that normal adult sensory axons can undergo extensive sprouting within a 
Figure 4. Photomicrographs of spinal cords injected with NGF/Adts showing the continued growth of CGRP-positive axons over time. $A$, Eight days after injection, axonal sprouting is apparent within lamina I-IV of the dorsal horn $(D)$ but not in the ventral horn $(G)$. B, Sixteen days after injection, the density of axons spouting throughout the dorsal horn $(E)$, lateral funiculus (lf), central canal $(c)$, and ventral horn $(H)$ had increased when compared with that observed $8 \mathrm{~d}$ earlier. Higher magnification of the dorsal $(E)$ and ventral $(H)$ regions shows numerous individual CGRP-positive fibers. $C$, Thirty-two days after injection the entire region expressing NGF becomes extremely dense with CGRP-positive fibers. $F$, Higher magnification of the dorsal horn demonstrates a density so great that individual axons cannot be distinguished. $I$, Within the ventral horn the number of axonal sprouts also increased but not as dramatically as in the dorsal horn. Scale bars: $B$ and $C$ same as $A ; E-I$ same as $D$.
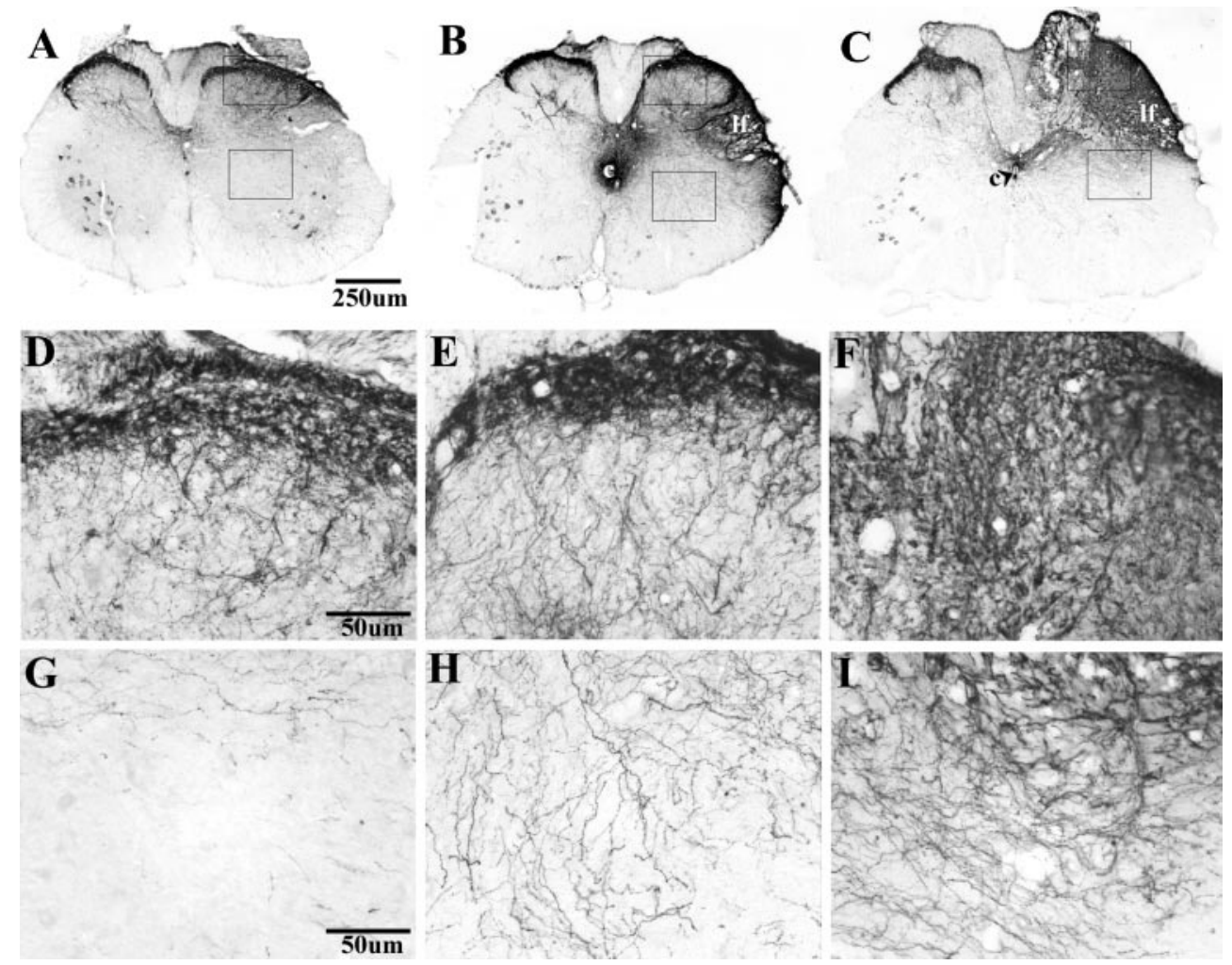

relatively short period of time (Table 1 ). This induced hyperinnervation was apparent both as increased CGRP immunoreactivity within proper targets (i.e., lamina I, II, and X) and as aberrant growth into areas normally not innervated by these fibers throughout lamina III-VI in the dorsal horn and laminae VII-IX in the ventral horn (Table 1).

Approximately 3 weeks after injection of the adenoviruses, transgene expression in the spinal cord begins to decline (Liu et al., 1997; Romero and Smith, 1998). To assess whether the NGFinduced sprouting of sensory fibers would continue beyond this time period, animals injected with NGF/Adts were evaluated for CGRP innervation at 8, 16, and $32 \mathrm{~d}$ after treatment (Fig. 4). In these animals, the amount of CGRP-immunopositive fibers displayed a continual increase in the density of axons within the dorsal and ventral horns. By $32 \mathrm{~d}$ after injection, the density of CGRP-positive axons throughout the entire dorsal spinal cord was quite impressive (Fig. 4C,F, Table 1). In many of these animals a discrete boundary of axonal growth was apparent and correlated with the zone of transgene expression (compare Fig. $2 A, B$ with $4 C, 5 A)$. Axons were observed extending not only within the dorsal and ventral horns but around the spinal canal and within the white matter of the lateral funiculus (Fig. 4B,C). In addition to $\mathrm{NGF} /$ Adts inducing robust sprouting, it was also extremely consistent: all but one ( $8 \mathrm{~d}$ after injection) of the injected animals showed extensive sprouting. In all of these animals, axonal sprouting was apparent throughout the injected region, which extended 8-10 $\mathrm{mm}$ within L4 and L5.

\section{Characterization of the sensory fibers sprouting after injection of NGF/Adts}

The neuronal population within the DRG is highly heterogeneous. Those neurons are either CGRP/trkA or IB4 nociceptors that send the majority of small caliber cutaneous sensory afferents to the dorsal horn (Snider and McMahon, 1998). The high-affinity
NGF tyrosine kinase receptor trkA mediates stereotypical NGF responses such as neurite outgrowth (Loeb and Greene, 1993) and growth cone turning (Gallo et al., 1997), whereas the lowaffinity neurotrophin receptor p75 is thought to function as a positive modulator of trkA activity (Lachance et al., 1997). In the adult DRG, virtually all of the trkA-containing neurons express CGRP, with many coexpressing substance-P (SP) neuropeptide (Averill et al., 1995; Molliver et al., 1995). Within the dorsal horn, these fibers innervate lamina I and outer lamina II (IIo), whereas the majority of IB4 axons express the enzymes FRAP and thiamine monophosphatase (TMP) and terminate in inner lamina II (IIi) (Snider and McMahon, 1998). To define the subtype of sensory afferent axons from the spinal cord of animals that showed CGRP hyperinnervation via NGF overexpression (Fig. $5 A, B)$, sections were processed for the localization of SPcontaining (Fig. 5C,D) and FRAP-containing (Fig. 5E, F) fibers. In these animals, the visualization of SP-labeled fibers closely resembled the same growth pattern throughout the gray and white matter as that observed with CGRP (Fig. 5, compare $A$ and $B$ with $C$ and $D$ ), although the overall fiber density was considerably reduced. In sharp contrast, terminals of FRAP-containing afferents were restricted to the appropriate lamina and were not affected at all by NGF overexpression in the dorsal spinal cord (Fig. 5E,F).

\section{Overexpression of NGF in the dorsal spinal cord results in hyperalgesia, guarding behavior, and impaired locomotion on a grid runway}

Sensory information from the hindlimbs enters the spinal cord primarily at lumbar segments 4 and 5, precisely the site of viral administration in this study. To determine whether overexpression of these NTFs within the dorsal spinal cord would affect the processing of sensory information, behavioral analyses were performed. Animals treated with the NTF-expressing adenoviruses 

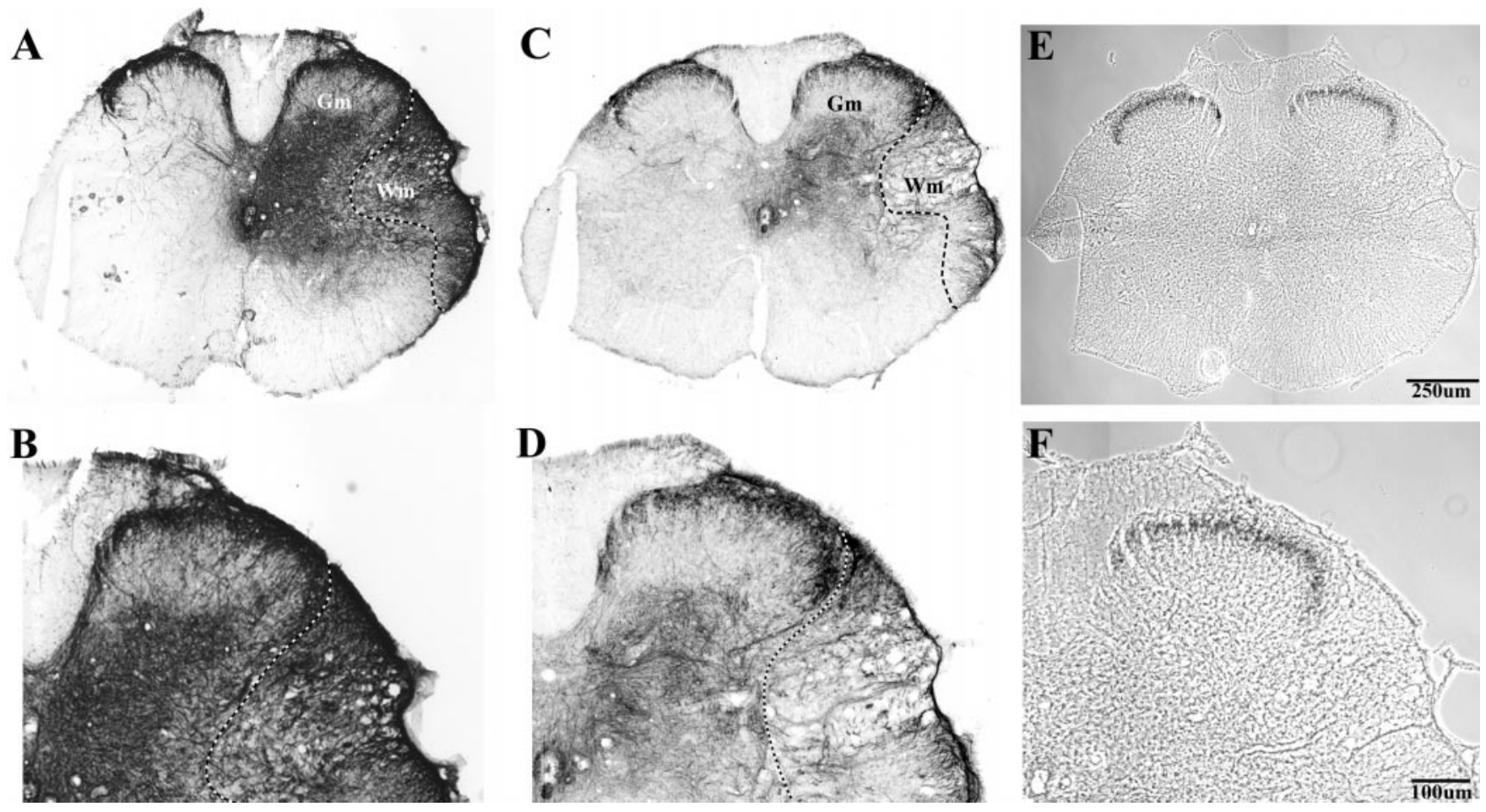

Figure 5. Photomicrographs of adjacent dorsal spinal cord sections of an animal $32 \mathrm{~d}$ after NGF/Ad administration. Immunological localization of CGRP-positive $(A, B)$ and substance-P-positive $(C, D)$ fibers revealed that sensory afferents expressing these two peptides extended neurites in response to NGF. These axons sprout within both the gray matter $(\mathrm{Gm})$ of the dorsal horn and the white matter $(\mathrm{Wm})$ of the lateral funiculus. Conversely, visualization of primary afferents expressing fluoride-resistant acidic phosphatase by histochemistry $(D, E)$ showed no response of these axons to NGF. Scale bars: $A$ and $C$ same as $E ; B$ and $D$ same as $F$.

Figure 6. Hyperalgesia and behavioral changes associated with the injection of NGF/Adts $(\bullet)$ and FGF-2/Adts $(\boldsymbol{\nabla})$, but not NT-3/Adts ( $\mathbf{\square})$. $A$, Nociceptive responses were evaluated by measuring the latency of paw withdrawal during thermal stimulation at $-1,8,16,24$, and $32 \mathrm{~d}$ after injection, and results show the difference between the right (experimental) and left (control) paw plotted. $B$, Accurate placement of the right (solid symbols) and the left (open symbols) paws was determined by examining the rats as they walked along a grid runway -1 , 8, 16, 24, and $32 \mathrm{~d}$ after adenoviral injections. Rats injected with NGF/Adts showed poor foot placement when compared with NT-3/Adts controls or the hindpaw contralateral (left) to the injected side. $C$, While at rest, all of the rats injected with NGF/Adts showed the guarding behavior, consisting of their holding the afflicted hindpaw against their belly (arrow), whereas animals injected with either FGF-2/Adts or NT-3/Adts $(D)$ did not show this behavior. Data are presented as the mean \pm SEM. ${ }^{*} p<$ $0.05 ; * *<0.01$.

A) Nociceptive Response
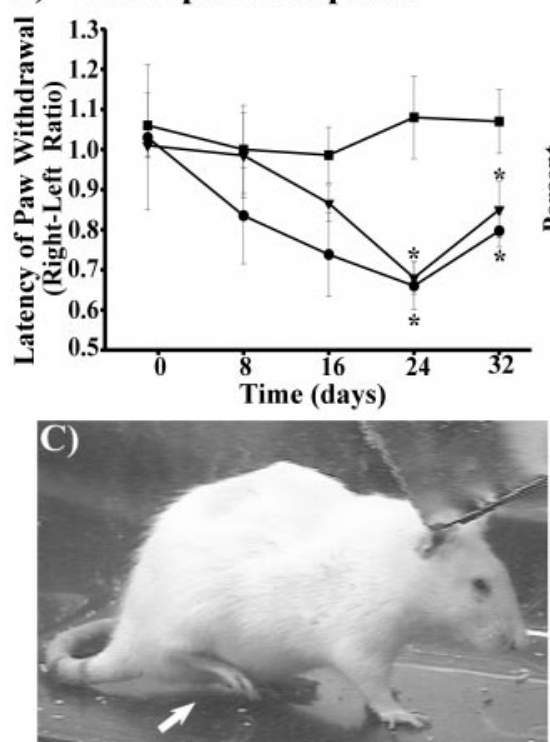

B) Grid Walking Response
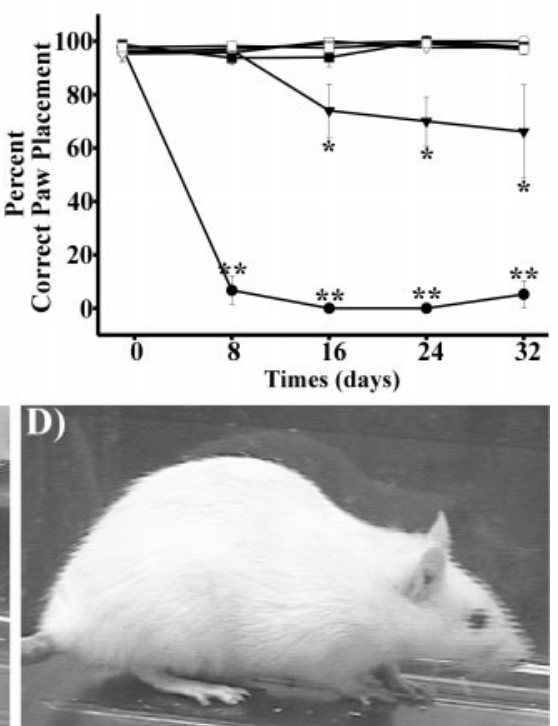

(FGF-2/Adts, NGF/Adts, and NT-3/Adts) were functionally evaluated for cutaneous nociception to thermal stimulation and foot placement (grid walking). The extensive hyperinnervation of the CGRP- and SP-positive fibers after NGF/Adts injections suggests the possibility that these animals may display hyperalgesia. Measurements for the latency of paw withdrawal from noxious thermal stimulation showed that NGF/Adts- and FGF-2/Adts-injected animals, but not NT-3-Adts-injected animals, were hypersensitive to thermal stimulation (Fig. 6A). This hypersensitivity cannot be attributed to any inflammatory response or the adenovirus itself, because our previous studies showed that identical injections of LacZ/Adts into the spinal cord cause no alteration in the nociceptive responses (Romero and Smith, 1998). NGF/Adts-injected rats showed the appearance of hyperalgesia within the first $8 \mathrm{~d}$ after injection, whereas the onset does not appear until the second week for FGF-2/Adts-injected animals. In all of these animals, no hyperalgesia was observed in the hindlimb contralateral to the injection sites, and the paw withdrawal latencies for all 
of the contralateral hindlimbs and the hindlimb ipsilateral to the NT-3/Adts injection were identical to preinjected baseline measurements.

Early in these experiments we observed that rats injected with NGF/Adts would often hold the ipsilateral hindpaw up tight against their body when at rest (Fig. 6C). This is a typical guarding behavior that is often observed in various pain models (Bennett, 1994). This behavior was observed exclusively in animals injected with NGF/Adts. To determine whether locomotive responses were also affected, animals were examined for proper foot placement while walking along a grid runway (KunkelBagden et al., 1993). Analysis of videotapes, in slow motion, showed that the ipsilateral hindlimb in animals injected with $\mathrm{NGF} /$ Adts was rarely placed directly onto the rungs of the grid runway, whereas the contralateral hindlimb was unaffected (Fig. $6 B)$. In most instances the rat would either guard the hindlimb or hyperextend the leg caudally as it walked. Animals that hyperextended their leg while walking on the grid runway showed no hindlimb paralysis while walking on a normal surface. These animals also showed hyperalgesic responses to thermal stimulation of the hindpaw ipsilateral to the injection (Fig. 6A). A less dramatic but statistically significant decrease in paw placement was also observed after injections of FGF-2/Adts (Fig. 6B). This response correlated with hyperalgesia that was observed after injection with FGF-2/Adts. It is interesting to note that no hyperinnervation of CGRP-positive fibers was histologically apparent in these animals. In summary, these data show that long-term expression of neurotrophins in the spinal cord can cause hyperinnervation of CGRP-positive sensory axons that results in aberrant sensory responses.

\section{DISCUSSION}

The well known trophic/tropic properties of NTFs and CAMs prompt interest for their potential use as a gene therapy-based treatment for the injured or diseased CNS (Breakfield et al., 1999). This study demonstrates relatively long-term and robust expression of the neurotrophins FGF-2, NGF, and NT-3 and the cellular adhesion molecules L1 and $\mathrm{N}-\mathrm{Cad}$ in the normal adult spinal cord after adenoviral injection. Intraparenchymal administration of adenoviruses into the dorsal spinal cord resulted in transgene expression primarily by astrocytes in the dorsal and motor neurons in the ventral spinal cord. This apparent regional variation might be caused by differences in vector spreading and cell-type susceptibility to adenovirus binding and endocytosis (Hermens et al., 1997). The uptake of adenoviruses into motor neurons in the ventral horn might also be mediated through their extensive dendritic arbors, which extend into the area surrounding the injection site.

\section{Collateral sprouting of primary sensory afferents induced by NGF gene transfer}

Conditional expression of NGF in the dorsal spinal cord resulted in extensive axonal growth of primary CGRP-containing fibers into the injected area in almost $100 \%$ of the NGF/Adts animals. The ability of these fibers to sprout in response to peripheral NGF administration is a well established phenomena (Diamond et al., 1992; Davies et al., 1997a). In the adult spinal cord, however, the effect of exogenous NGF appears to depend on the administration route. Intrathecal or subcutaneous administration of NGF upregulates the expression of neuropeptides and BDNF within dorsal ganglion neurons (Verge et al., 1995; Michael et al., 1997a). This administration route also induces central release of neuropeptides (Malcangio et al., 1997a) but failed to promote collateral sprouting in the spinal cord (Verge et al., 1995). Conversely, transgenic mice engineered to overexpress NGF in keranocytes (Mendelson et al., 1996), oligodendrocytes (Ma et al., 1995), or astrocytes (Kawaja et al., 1997) resulted in collateral growth of axons toward sites of NGF expression, including both normal and aberrant targets. In the present study, we provide conclusive evidence that overexpression of NGF within the adult spinal cord results in extensive spouting of primary nociceptive fibers at a magnitude and density of axonal growth dramatically higher than that reported previously.

The observed amount of fiber growth may reflect a higher and/or more prolonged level of NGF expression achieved in the spinal cord by our in vivo gene transfer method. In this study, adenoviral-mediated expression of NGF over the entire $8 \mathrm{~mm}$ ipsilateral side of the spinal cord is estimated to be $\sim 5 \mathrm{ng} / \mathrm{mg}$ of spinal cord. These results are in accordance with previous in vitro ELISA analyses of similar constructs (Smith et al., 1996). These levels are also significantly higher than those of endogenous NGF (Korsching and Thoenen, 1985; Bennet et al., 1999) and those achieved in NGF-expressing transgenic mice (Kawaja and Crutcher, 1997). In addition, the use of adenoviruses to directly transfect glia might further increase the sprouting potential of NGF by enhancing the growth-supportive nature of the endogenous cellular environment. These observations highlight the importance of restricting the expression of NGF in the spinal cord, both spatially and temporally, to prevent the occurrence of aberrant collateral sprouting.

In many of the animals that were injected with NGF/Adts, we observed CGRP- and SP-positive axons growing into myelinated regions of the lateral funiculus, which should be inhibitory to axonal growth (Schnell and Schwab, 1990). The NGF-induced growth of nociceptive fibers into these myelinated areas has previously been reported and attributed to the ability of neurotrophins to desensitize growing axons to myelin inhibition (Ma et al., 1995). However, because those observations were made in transgenic mice engineered to express NGF by oligodendrocytes, the possibility of fiber growth occurring at immature stages or the disruption of this inhibition by the genetically altered oligodendrocytes complicates their interpretation. In this study, the fact that fully mature neurons extend collateral fibers into myelinated areas modified to express NGF provides strong evidence that adult neurons can be induced to grow into myelinated regions. Although the detailed mechanism for this effect remains to be elucidated, recent in vitro evidence suggests that pretreatment of neurons with NGF can override myelin-induced inhibition, most likely by elevating cAMP levels and activating protein kinase A-dependent events within those neurons (Cai et al., 1999). The possibility that adenovirus induced demyelination, and consequently, the reduced inhibitory properties of myelin, is an unlikely explanation, because axonal growth into white matter was not generally observed after treatment with other adenoviruses (LacZ/Adts, L1/adts, N-Cad/Adts, NT-3/Adts) but was specific for NGF/Adts. In addition, recent evidence by Davies et al., (1997b, 1999) strongly suggests that axons can readily grow through intact myelinated regions but stop when they contact chondroitin sulfate proteoglycan at a lesion site. Under such a condition, the neurotrophin might act to stimulate the intrinsic grow state of the axons to grow past the entry zone and continue growing through the dorsal cord without much hindrance. 


\section{Characterization of the NGF-induced axonal growth}

In the dorsal spinal cord, CGRP is regarded as a reliable marker for primary afferents (Traub et al., 1989), labeling $\sim 40-45 \%$ of the projections from DRG neurons. Many of the CGRP-positive DRG neurons, in addition to trkA, also coexpress p75 (Wright and Snider, 1995; Michael et al., 1997b) and substance-P (Plenderleith et al., 1990). Therefore, it is not surprising that in our study CGRP- and SP-positive fibers would undergo collateral axonal growth in response to NGF. Conversely, the IB4 class of nociceptors selectively expresses the FRAP and TMP enzymes, are GDNF-sensitive, and express Ret receptors (Molliver et al., 1997). The observed normal distribution of FRAP-containing fibers (lamina IIi) after injections of NGF/Adts concurs with the fact that these neurons do not express the trkA or $\mathrm{p} 75$ receptors. The neurons therefore remain unchanged, whereas CGRP/trkApositive nociceptive axons sprout extensively within the same area.

\section{Hyperalgesia}

Nociceptive fibers innervating the rat hindpaw skin originate from DRG neurons in the lumbar segments 4 and 5 (Swett and Woolf, 1985; Rivero-Melian and Grant, 1990). In adult rats, subcutaneous administration of NGF induces thermal hyperalgesia within minutes that appears to be mediated by both peripheral and central mechanisms (Lewin et al., 1993; Woolf,1996; Malcangio et al., 1997b). The effect of NGF administration in the spinal cord is less well defined. In a recent study, transgenic mice in which NGF expression was driven by the GFAP promoter showed thermal hyperalgesia when compared with wild-type littermates (Ramer et al., 1998). In this transgenic line, however, axonal growth of CGRP-positive fibers occurred primarily within the cerebellum (Kawaja et al., 1997), and the resultant hyperalgesia was thought to be the result of sympathetic sprouting of adrenergic fibers into the DRG (Ramer et al., 1998). In the present study, the production of NGF by cells within the dorsal horn led to hyperinnervation by nociceptive fibers and induced hyperalgesia. We also observed that NGF/Adts-treated animals displayed a distinctive guarding behavior of the ipsilateral hindlimb. This behavior was discernible both while the animal was at rest and while walking on a grid runway but not during ambulation on a solid surface. Guarding behavior is observed in several animal models of pain and is a common clinical finding in patients suffering from chronic pain (Bennett, 1994).

Interestingly, the injection of FGF-2/Adts resulted in thermal hyperalgesia and a slight reduction in proper foot placement while walking on a grid runway but no apparent guarding behavior. Examination of CGRP- and SP-positive fibers, however, showed no hyperinnervation or perceptible alteration of normal innervation pattern, even $32 \mathrm{~d}$ after injection. The effect of FGF-2 on hyperalgesia was not as severe as that of NGF. This may have been caused more by a local augmentation of the endogenous neuronal circuits, such as inducing vesicle clustering at the synapse (Dai and Peng, 1995) or reducing GABA-evoked currents (Tanaka et al., 1996) that act to suppress the perception of pain. FGF-2 may also indirectly induce axon sprouting by stimulating the expression of NGF by astrocytes (Yoshida and Gage, 1992). Our ELISA data of FGF-2/Adts-injected spinal cords show a moderate $(190 \%)$ but statistically significant increase in the expression of NGF. These lower levels may contribute to a slow but progressive axonal sprouting. Previous studies showed that FGF2-expressing fibroblasts induce sprouting of CGRP-positive fibers similar to NGF; however, the FGF-2-induced sprouting occurs much more slowly, often taking several months to become apparent (Nakahara et al., 1996). Under these conditions, behavioral responses such as hyperalgesia may be observed before the appearance of sprouting fibers in atypical locations.

This study represents the first observation that NGF or FGF-2 overexpression in the spinal cord induces hyperalgesia. Animals injected with NGF/Adts also displayed a guarding behavior that directly correlates to central collateral sprouting of nociceptive primary afferents. The mechanisms underlying hyperalgesia in these animals are still unclear, but several possibilities, alone or in combination, can be envisioned as possible explanations: (1) a net increase in functional nociceptive terminals within the normal target region (lamina II) that increase the excitatory tone of the primary afferent pathway; (2) functional innervation of nociceptive fibers into aberrant targets that induce pain perception by activating otherwise unrelated pathways; (3) if the sprouting axons fail to form functional synaptic connection, then hyperalgesia could be attributable to an increase in neurotransmitter synthesis and release by fibers within the normal target region (Verge et al., 1995; Malgangio et al., 1997). The negative side effect of chronic pain further illustrates that gene therapy vectors need to be designed with more stringent control of growth factor or neurotrophin expression. Tighter control, such as the use of inducible promoters, might allow for the restoration of damaged circuits after injury or disease while sparing the normal circuitry of adjacent undamaged neurons.

\section{REFERENCES}

Aubert I, Ridet J-L, Gage FH (1995) Regeneration of the adult mammalian CNS: guided by development. Curr Opin Neurobiol 5:625-635.

Averill S, McMahon SB, Clary SB, Reichardt LF, Priestley JVP (1995) Immunocytochemical localization of trkA receptors in chemically identified subgroups of adult rat sensory neurons. Eur $\mathrm{J}$ Neurosci 7:1484-1494.

Baumgartner BJ, Shine HD (1998) Neuroprotection of spinal motoneurons following targeted transduction with an adenoviral vector carrying the gene for glial cell line-derived neurotrophic factor. Exp Neurol 153:102-112.

Bennett GJ (1994) Animal models of neuropathic pain In: Progress in pain research and management, Vol 2 (Gebhart GF, Hammond DL, Jensen TS, eds), pp 495-510. Seattle: IASP.

Brackenbury R, Thiery JP, Rutishauser U, Edelman GM (1997) Adhesion among neural cells of the chick embryo. I. An immunological assay for molecules involved in cell-cell binding. J Biol Chem 252:68356840 .

Breakfield X, Jacobs A, Wang S (1999) Genetic engineering for CNS regeneration. In: $\mathrm{CNS}$ regeneration. Basic science and clinical advances (Tuszynski MH, Kordower J, eds), pp 251-291. San Diego: Academic.

Byrnes AP, Rusby JE, Wood MJA, Charlton HM (1995) Adenovirus gene transfer causes inflammation in the brain. Neuroscience 66:1015-1024.

Cai D, Shen Y, De Bellard M, Tang S (1999) Prior exposure to neurotrophins block inhibition of axonal regeneration by MAG and myelin via a cAMP-dependent mechanism. Neuron 22:89-101.

Choi-Lundberg DL, Lin Q, Chang YN, Chiang YL, Hay CM, Mohajeri H, Davidson BL, Bohn MC (1997) Dopaminergic neurons protected from degeneration by GDNF gene therapy. Science 275:838-841.

Chung K, Lee WT, Carlton SM (1988) The effects of dorsal rhizotomy and spinal cord isolation on calcitonin gene-related peptide-labeled terminals in the rat lumbar dorsal horn. Neurosci Lett 90:27-32.

Dai Z, Peng HB (1995) Presynaptic differentiation induced in cultured neurons by local application of basic fibroblast growth factor. J Neurosci 13:5466-5475.

Davies BM, Fundin BT, Albers KM, Goodness TP, Cronk KM, Rice FL (1997a) Overexpression of nerve growth factor in skin causes preferential increases among innervation to specific sensory targets. J Comp Neurol 387:489-506.

Davies SJ, Fitch MT, Memberg SP, Hall AK, Raisman G, Silver J (1997b) regeneration of adult axons in white matter tracts of the central nervous system. Nature 390:680-683. 
Davies SJ, Goucher D, Dollar C, Silver J. (1999) Robust regeneration of adult sensory axons in degenerating white matter of the adult rat spinal cord. J Neurosci 19:5810-5822.

Diamond J, Holmes M, Coughlin M (1992) Endogenous NGF and nerve impulses regulate the collateral sprouting of sensory axons in the skin of the adult rat. J Neurosci 12:1454-1466.

Dijkhuizen PA, Verhaagen J (1999) The use of neurotrophic factors to treat spinal cord injury: advantages and disadvantages of different delivery methods. Neurosci Res Commun 24:1-10.

Dijkhuizen PA, Hermens WTJMC, Teunis MAT, Verhaagen J (1997) Adenoviral vector-directed expression of neurotrophin-3 in rat dorsal root ganglion explants results in a robust neurite outgrowth response. J Neurobiol 33:172-184.

Fitch MT, Silver J (1999) Beyond the glial scar. Cellular and molecular mechanism by which glial cells contribute to CNS regenerative failure. In: CNS regeneration: basic science and clinical advances (Tuszynski MH, Kordower J, eds), pp 55-87. San Diego: Academic.

Gallo G, Lefcort FB, Letourneau PC (1997) The trkA receptor mediates growth cone turning toward a localized source of nerve growth factor. J Neurosci 17:5445-5454.

Garry MG, Richardson JD, Hargreaves KM (1994) Carrageenaninduced inflammation alters the content of i-cGMP and i-cAMP in the dorsal horn of the spinal cord. Brain Res 646:135-139.

Gibson SJ, Polak JM, Bloom SR, Sabate IM, Mulderry PM, Ghatei MA, McGregor GP, Morrison JFB, Kelley JS, Evans RM, Rosenfeld MG (1984) Calcitonin gene related peptide immunoreactivity in the spinal cord of man and of eight other species. J Neurosci 4:3101-3111.

Gravel C, Gotz R, Lorrain A, Sendtner M (1997) Adenoviral gene transfer of ciliary neurotrophic factor and brain-derived neurotrophic factor leads to long-term survival of axotomized motor neurons. Nat Med 3:765-770.

Guest JD, Hesse D, Schnell L, Schwab ME, Bunge MB, Bunge RP (1997) Influence of IN-1 antibody and acidic FGF-fibrin glue on the response of injured corticospinal tract axons to human Schwann cell grafts. J Neurosci Res 50:888-905.

Haase G, Kennel P, Pettmann B, Vigne E, Akli S, Revah F, Schmalbruch H, Kahn A (1997) Gene therapy of murine motor neuron disease using adenoviral vectors for neurotrophic factors. Nat Med 3:429-436.

Hargreaves KM, Dubner R Brown F, Flores C, Joris J (1988) A new and sensitive method for measuring thermal nociception in cutaneous hyperalgesia. Pain 32:77-88.

Hermens WT, Verhaagen J (1998) Viral vectors, tools for gene transfer in the nervous system. Prog Neurobiol 55:399-432.

Hermens WT, Giger RJ, Holtmaat AJ, Dijkhuizen PA, Houweling DA, Verhaagen J (1997) Transient gene transfer to neurons and glia: analysis of adenoviral vector performance in the CNS and PNS. J Neurosci Methods 71:85-98.

Holtmaat AJ, Oestreicher AB, Gispen WH, Verhaagen J (1998) Manipulation of gene expression in the mammalian nervous system: application in the study of neurite outgrowth and neuroregeneration-related proteins. Brain Res Rev 26:43-71.

Honig MG, Petersen GG, Rutishauser US, Camilli SJ (1998) In vitro studies of growth cone behavior support a role for fasciculation mediated by cell adhesion molecules in sensory axon guidance during development. Dev Biol 204:317-326.

Hortsch M (1996) The L1 family of neural cell adhesion molecules: old proteins performing new tricks. Neuron 17:587-593.

Kawaja MD, Crutcher KA (1997) Symathetic axons invade the brains of mice overexpressing nerve growth factor. J Comp Neurol 383:60-72.

Kawaja MD, Walsh GS, Petruccelli K, Coome GEA (1997) Sensory nociceptive axons invade the cerebellum of transgenic mice expressing nerve growth factor. Brain Res 774:77-86.

Kobayashi S, Miura M, Asou H, Inoue HK, Ohye C, Uyemura K (1995) Grafts of genetically modified fibroblasts expressing neural cell adhesion molecule L1 into transected spinal cord of adult rats. Neurosci Lett 188:191-194.

Korsching S, Thoenen H (1985) Nerve growth factor supply for sensory neurons: site of origin and competition with the sympathetic nervous system. Neurosci Lett 54:201-205.

Kunkel-Bagden E, Dai HN, Bregman BS (1993) Methods to assess the development and recovery of locomotor function after spinal cord injury in rats. Exp Neurol 119:153-164.

Lachance C, Belliveau DJ, Barker PA (1997) Blocking nerve growth factor binding to the p75 neurotrophin receptor on sympathetic neu- rons transiently reduces trkA activation but does not affect neuronal survival. Neuroscience 81:861-871.

Lewin GR, Ritter AM, Mendell LM (1993) Nerve growth factorinduced hyperalgesia in the neonatal and adult rat. J Neurosci 13:2136-2148

Lindsay RM, Wiegand SJ, Altar CA, DiStefano PS (1994) Neurotrophic factors: from molecule to man. Trends Neurosci 17:182-190.

Liu Y, Himes BT, Moul J, Huang W, Chow SY, Tessler A, Fischer I (1997) Application of recombinant adenovirus for in vivo gene delivery to spinal cord. Brain Res 768:19-29.

Loeb DM, Greene LA (1993) Transfection with trk restores "slow" NGF binding, efficient NGF uptake, and multiple NGF responses to NGFnonresponsive PC12 cell mutants. J Neurosci 13:2919-2929.

Ma W, Ribeiro-da-Silva A, Noel G, Julien JP, Cuello AC (1995) Ectopic substance $\mathrm{P}$ and calcitonin gene-related peptide immunoreactive fibres in the spinal cord of transgenic mice over-expressing nerve growth factor. Eur J Neurosci 7:2021-2035.

Malcangio M, Garrett NE, Tomlinson DR (1997a) Nerve growth factor treatment increases stimulus-evoked release of sensory neuropeptides in the rat spinal cord. Eur J Neurosci 9:1101-1104.

Malcangio M, Garrett NE, Cruwys S, Tomlinson DR. (1997b) Nerve growth factor- and neurotrophin-3-induced changes in nociceptive threshold and the release of substance $\mathrm{P}$ from the rat isolated spinal cord. J Neurosci 17:8459-8467.

Manthorpe M, Fagnani R, Skaper SD, Varon S (1986) An automated colorimetric microassay for neuronotrophic factors. Brain Res 390:191-198.

Mendelson B, Albers KM, Goodness TP, Davis BM (1996) Overexpression of nerve growth factor in epidermis of transgenic mice preserves excess sensory neurons but does not alter the somatotopic organization of cutaneous nerve projections. Neurosci Lett 211:68-72.

Michael GJ, Averill S, Nitkunan A, Rattray M, Bennett DHL, Yan Q, Priestley JV (1997a) Nerve growth factor treatment increases brainderived neurotrophic factor selectively in trkA-expressing dorsal root ganglion cells and in their central terminations within the spinal cord. J Neurosci 17:8476-8490.

Michael GJ, Kaya E, Averill S, Rattray M, Clary DO, Priestley JV (1997b) TrkA immunoreactive neurones in the rat spinal cord. J Comp Neurol 385:441-455.

Molliver DC, Radeke MJ, Feinstein SC, Snider WD (1995) Presence or absence of trkA protein distinguishes subsets of small sensory neurons with unique cytochemical characteristics and dorsal horn projections. J Comp Neurol 361:404-416.

Molliver DC, Wright DE, Leitner ML, Parsadanian AS, Doster K, Wen D, Yan Q, Snider WD (1997) IB4-binding DRG neurons switch from NGF to GDNF dependence in early postnatal life. Neuron 19:849-861.

Nakahara Y, Gage FH, Tuszynski MH (1996) Grafts of fibroblasts genetically modified to secrete NGF, BDNF, NT-3, or basic FGF elicit differential responses in the adult spinal cord. Cell Transplant 5:191-204.

Plenderleith MB, Haller CJ, Snow PJ (1990) Peptide coexistence in axon terminals within the superficial dorsal horn of the rat spinal cord. Synapse 6:344-450.

Ramer MS, Kawaja MD, Henderson JT, Roder JC, Bisby MA (1998) Glial overexpression of NGF enhances neuropathic pain and adrenergic sprouting into DRG following chronic sciatic constriction in mice. Neurosci Lett 251:53-56.

Rivero-Melian C, Grant G (1990) Distribution of lumbar dorsal root fibers in the lower thoracic and lumbosacral spinal cord of the rat studied with choleragenoid horseradish peroxidase conjugate. J Comp Neurol 299:470-481.

Romero MI, Smith GM (1998) Adenoviral gene transfer into the normal and injured spinal cord: enhanced transgene stability by combined administration of temperature-sensitive virus and transient immune blockade. Gene Ther 5:1612-1621.

Schnell L, Schwab ME (1990) Axonal regeneration in the rat spinal cord produced by an antibody against myelin-associated neurite growth inhibitors. Nature 343:269-272.

Schwab ME, Bartholdi D (1996) Degeneration and regeneration of axons in the lesioned spinal cord. Physiol Rev 76:319-370.

Senut M-C, Aubert I, Horner PJ, Gage FH (1998) Gene transfer for adult CNS regeneration and aging. In: Gene therapy for neurological disorders and brain tumors (Chiocca EA, Breakefiled XO, eds), pp 345-375. Totowa, NJ: Humana.

Smith G, Hale J, Pasnikowski E, Linsday R, Wong V, Rudge J (1996) 
Astrocytes infected with replication-defective adenovirus containing a secreted form of CNTF or NT3 show enhanced support of neuronal populations in vitro. Exp Neurol 139:156-166.

Smith GM, Romero MI (1999) Adenoviral-mediated gene transfer to enhance neuronal survival, growth, and regeneration. J Neurosci Res 55:147-157.

Snider WD, McMahon SP (1998) Tackling pain at the source: new ideas about nociceptors. Neuron 20:629-632.

Swett JE, Woolf CJ (1985) The somatotopic organization of primary afferent terminals in the superficial laminae of the dorsal horn of the rat spinal cord. J Comp Neurol 231:66-77.

Tanaka T, Saito H, Matsuki N (1996) Basic fibroblast growth factor modulates synaptic transmission in cultured rat hippocampus neurons. Brain Res 723:190-195.

Traub RJ, Solodkin A, Ruda MA (1989) Calcitonin gene-related peptide immunoreactivity in the cat lumbosacral spinal cord and the effects of multiple dorsal rhizotomies. J Comp Neurol 287:225-237.

Tuszynski MH (1999) Neurotrophic factors. In: CNS regeneration: basic science and clinical advances (Tuszynski MH, Kordower J, eds), pp 109-158. San Diego: Academic.

Varon S, Conner JM (1994) Nerve growth factor in CNS repair. J Neurotrauma 11:473-486.

Verge VMK, Richardson PM, Wiesenfeld-Hallin Z, Hškfelt T (1995)
Differential influence of nerve growth factor on neuropeptide expression in vivo: a novel role in peptide suppression in adult sensory neurons. J Neurosci 15:2081-2096.

Walsh FS, Doherty P (1997) Neural cell adhesion molecules of the immunoglobulin superfamily: role in axon growth and guidance. Annu Rev Cell Dev Biol 13:425-456.

Wemme H, Pfeifer S, Heck R, Muller-Quernheim J (1992) Measurement of lymphocyte proliferation: critical analysis of radioactive and photometric methods. Immunobiology 185:78-89.

Woolf CJ (1996) Phenotypic modification of primary sensory neurons: the role of nerve growth factor in the production of persistent pain. Philos Trans R Soc Lond B Biol Sci 351:441-448.

Wright DE, Snider WD (1995) Neurotrophin receptor mRNA expression defines distinct populations of neurons in rat dorsal root ganglia. J Comp Neurol 351:229-238.

Yoshida K, Gage FH (1992) Cooperative regulation of nerve growth factor synthesis and secretion in fibroblasts and astrocytes by fibroblast growth factor and other cytokines. Brain Res 569:14-25.

Zhang Y, Dijkhuizen PA, Anderson PN, Lieberman AR, Verhaagen J (1998) NT-3 delivered by an adenoviral vector induces injured dorsal root axons to regenerate into the spinal cord of adult rats. J Neurosci Res 54:554-562. 